\title{
Mothers impose physical activity restrictions on their asthmatic children and adolescents: an analytical cross-sectional study
}

\author{
Fabianne MNA Dantas ${ }^{1}$, Marco AV Correia $\mathrm{Jr}^{2}$, Almerinda R Silva ${ }^{3}$, Décio M Peixoto ${ }^{3}$, Emanuel SC Sarinho ${ }^{3}$
} and José A Rizzo ${ }^{4 *}$

\begin{abstract}
Background: Physical activities are important for children and adolescents, especially asthmatics. A significant proportion is considered less active than their non-asthmatic peers and mother's beliefs about asthma are thought to be a determinant factor.

The research objectives were to investigate whether mothers try to impose limitations on the physical activity (PA) of their asthmatic children/adolescents; identify associated factors; and explore if this attitude has any impact on children's PA levels.

Methods: In this cross sectional investigation, we studied 115 asthmatics aged between 9 and 19 years and their mothers. Asthma severity, PA level and exercise induced bronchospasm (EIB) were evaluated. Mothers were questioned on their beliefs about physical activity in non-asthmatic and asthmatic children, if they imposed restrictions on their children's physical activity, on EIB perception and personal levels of anxiety and depression.

Results: Ninety six percent of the mothers answered that PA are important for children and adolescents. Despite this, 37\% of them admitted imposing restrictions to their children's PA. This attitude was associated with mother's negative opinions about asthmatics doing PA, perception of children's dyspnea after running on a treadmill, mother's anxiety level and children's asthma severity. The mother's restrictive attitudes were not associated with children's lower PA levels.

Conclusion: A high proportion of the mothers said that they restrained their asthmatic children from engaging in physical activity. This fact should be recognized by health professionals and discussed with parents and caregivers as these negative beliefs may lead to conflicts and prejudiced attitudes that could discourage children's

involvement in physical activities and sports.
\end{abstract}

Keywords: Asthma, Child, Adolescent, Physical activity, Restriction

\section{Background}

Regular physical activity (PA) by children and adolescents with asthma is associated both with an improvement of disease control and quality of life and with a reduction in exacerbations, hospital admissions, school absenteeism, unscheduled medical visits and the number of medications used to control asthma [1-5]. Participating

\footnotetext{
* Correspondence: jarizzo@hotlink.com.br

${ }^{4}$ Center for Research in Allergy and Clinical Immunology. Clinical Medicine Department - Pneumology, Universidade Federal de Pernambuco, Recife, Brazil

Full list of author information is available at the end of the article
}

in games, playing around and engaging in sports or physical education at school are also activities that promote children's social inclusion and relationships, thus preventing psychological and social isolation and improving selfesteem, encouraging an active and healthy lifestyle [6].

Physical activities and sports are considered safe for asthmatics, recommended as a part of their treatment and should not be avoided. This is true even in patients with a diagnosis of exercise-induced bronchospasm (EIB) provided they are adequately monitored and prophylactically treated [7-9]. However, there are evidences that children and adolescents with asthma are less active than 
their non-asthmatic peers and a maternal negative influence has been identified as a limiting factor [10-12]. On the other hand, when encouraged by their mothers, children become more active [13].

As it is usually the mothers who take care of asthmatic children and adolescents, it is possible that those who think that asthma symptoms can be triggered or worsened by taking part in PA do not encourage or even forbid their children from doing so in order to avoid symptoms, contributing to the inactivity of their children $[12,14,15]$. Other factors may contribute to the mother's restrictive attitudes such as negative expectations with regard to PA, anxiety, depression, negative experiences, misperceptions, distorted opinions about physical exercise in asthmatics and the lack of adequate information about the disease [10,15-20].

The objective of this study was to investigate whether the mothers in an urban community imposed restrictions on the physical activity of their asthmatic children, to identify possible factors related to this attitude and to check if there was an association between this behavior and the amount of children's and adolescent's PA.

\section{Methods}

\section{Study design and sample}

This was an analytical cross-sectional study conducted at the Pulmonary Functional Laboratory of the Hospital das Clínicas at the Federal University of Pernambuco (UFPE) - Brazil. Data were collected between November 2008 and September 2009. The study was approved by the institutional ethics committee and the mothers agreed and signed an informed consent document.

The mothers and their respective offspring aged between nine and nineteen were recruited at a specialized public clinic. The children had been previously diagnosed as having asthma by an allergist or pulmonologist and were referred to the Pulmonary Function Laboratory to investigate EIB.

The patients involved in the analysis did not have an acute exacerbation during the period of data collection, were without symptoms of respiratory infection in the last six weeks and had a forced expiratory volume in one second $\left(\mathrm{FEV}_{1}\right)$ at baseline $\geq 60 \%$ of the predicted value. Patients were excluded who did not meet these requirements, were outside the age range, had other conditions that would preclude running on a treadmill, were using oral steroids. Patients unable to perform the forced expiratory maneuver for the spirometry test and those who were accompanied by guardians other than their mothers were also excluded.

Asthma severity was classified according the Global Initiative for Asthma (GINA) criteria as intermittent or persistent, mild, moderate or severe [8]. For the analysis, the first two and the last two categories were grouped.
Asthma medications were interrupted according the recommendations of the American Thoracic Society (ATS) for exercise challenge testing [21]. Nutritional status was determined according the criteria of the World Health Organization (WHO) [22].

\section{Data collection - questionnaires}

General data was collected about the patients (age, sex, weight, height and BMI) as well as information concerning family income and the mother's level of education. To assess the level of physical activity, children and adolescents answered the short version of the International Physical Activity Questionnaire (IPAQ), translated into Portuguese and validated for Brazil [23]. This questionnaire takes into account activities engaged in for at least ten minutes continuously in the previous week based upon reports of exercise frequency, intensity and duration and classifies individuals as being very active, active, irregularly active A and B and sedentary. For the analysis individuals were considered active when they were classified as very active or active and as inactive when they were classified as irregularly active or sedentary [24].

On the same day, mothers were asked to answer a questionnaire to examine if they imposed restrictions on PA as well as their previous perception about children having EIB and their opinions on asthmatics doing PA. PA restrictions imposed by the mothers were determined by the response to the question "Do you prevent your child from taking part in sports or games because of asthma in the period when he/she is not having an attack?".

The mother's perception of EIB was evaluated at two points in time: before and after the exercise test. Before the test, the mother's response to the following question was considered: "Does your child have wheezing or asthma when at play or taking part in sports?" Then, the mother's perception of EIB was evaluated by requesting them to mark a point on the visual analogue scale (VAS) that consisted of a $10 \mathrm{~cm}$ horizontal line, anchored on the far left by the phrase "no shortness of breath," and on the far right end by "great shortness of breath". The measurement was made five minutes after children had been running on the treadmill, immediately before the second spirometry test. The point marked was measured in centimeters $(1-10 \mathrm{~cm})$ [16].

The mother's opinions on children in general and children with asthma engaging on physical exercise were evaluated using the following questions adapted from Lang et al. [15]: "Is doing exercise important for children?", "Are you afraid that your child will fall ill if he/she does exercise?" and "Is exercise dangerous for children with asthma?". In addition, they also answered the Hospital Anxiety and Depression Scale (HADS) questionnaire translated into Portuguese and validated for Brazil [25,26]. 


\section{Exercise testing}

After responding to the IPAQ, patients underwent basal $\mathrm{FEV}_{1}$ measurement and then ran on a treadmill (Athletic Way Advanced - Brazil) for 8 to 9 minutes achieving at least $80 \%$ of maximum heart rate for the last 6 minutes [21]. $\mathrm{FEV}_{1}$ was again measured at 5, 15 and 30 minutes after running. The MicroQuark ${ }^{\circ}$ spirometer (Cosmed Rome - Italy) calibrated daily was used for spirometries that were performed according to ATS/ERS recomendations [27]. The test was considered positive for EIB if there was a $\mathrm{FEV}_{1}$ reduction $\geq 10 \%$ from baseline. The values predicted for $\mathrm{FEV}_{1}$ were calculated from the reference equation for Brazilian children and adolescents [28].

All tests were carried out in the morning, in an airconditioned room (temperature $21^{\circ} \mathrm{C}-23^{\circ} \mathrm{C}$ and relative humidity $60 \%-80 \%$ ). Peripheral oxygen saturation and heart rate were monitored continuously using the pulse oximeter $\left(\mathrm{GE}^{\circ}\right.$ Marquette Solar 8000 - USA) and a heart rate sensor (Polar RS100 - Finland).

Each stage was conducted by trained researchers who were supervised by a coordinator and data were collected according to the flowchart shown in Figure 1. Participants unable to answer the questionnaire because they were illiterate were interviewed.

\section{Statistical analysis}

After an initial analysis, mothers and their children were separated into two groups: one with mothers who reported imposing restrictions on their children's physical activities and the other with mothers who did not. Each of the predictive variables was checked by comparing proportions using the Chi-squared test and odds ratio (ORs) with 95\% confidence intervals (CIs) in order to select those that were associated with mother's attitude towards PA. These variables were then used for the construction of a multivariate regression model. The visual analog scale was dichotomously categorized as $<5 \mathrm{~cm}$ and $\geq 5 \mathrm{~cm}$. HADS anxiety and depression scales scores were categorized as $>9$ and $\leq 9$ as this cut off point showed the best sensitivity/specificity discrimination relationship [25]. To check the association between the mother's attitude and the children's PA level, the chisquare test was used. A probability $<0.05$ was considered significant. Data were analyzed using SPSS for Windows, version 12.0 (SPSS Inc, Cary, North Carolina- USA).

\section{Results}

Evaluations were made on 115 pairs of mothers and their offspring. The children's general characteristics are shown in Table 1. Of the 115 children/adolescents, 8\% were obese (BMI $>30), 7 \%$ were overweight $(25<\mathrm{BMI}<$ $29.9), 82 \%$ had normal weight $(18.5<\mathrm{BMI}<24.9)$ and $3 \%$ were underweight $(\mathrm{BMI}<18.5)$. Of the 115 mothers, $10 \%$ were illiterate, $63 \%$ had completed elementary school and $27 \%$ high school.

Of all the mothers, 37\% said they impose restrictions on their children's physical activities (sports/games) in periods when they were not suffering an asthma exacerbation, and $63 \%$ said they did not limit PA. Table 2 shows the results of univariate analysis of associated factors. The mother's restrictive attitude was not associated with the physical activity levels of their children $(p=0.9)$ nor BMI index, gender, medication use or family income $(\mathrm{p}=>0.99, \mathrm{p}=0.70, \mathrm{p}=0.82, \mathrm{p}=0.47$ respectively). Also, there was no association between children's asthma severity and PA levels $(\mathrm{p}=0.58)$.

After the multivariate analysis, it was found that the fear that the child would fall ill if he/she does exercises was significantly associated with the mother's PA restriction. Other factors that were significantly associated with

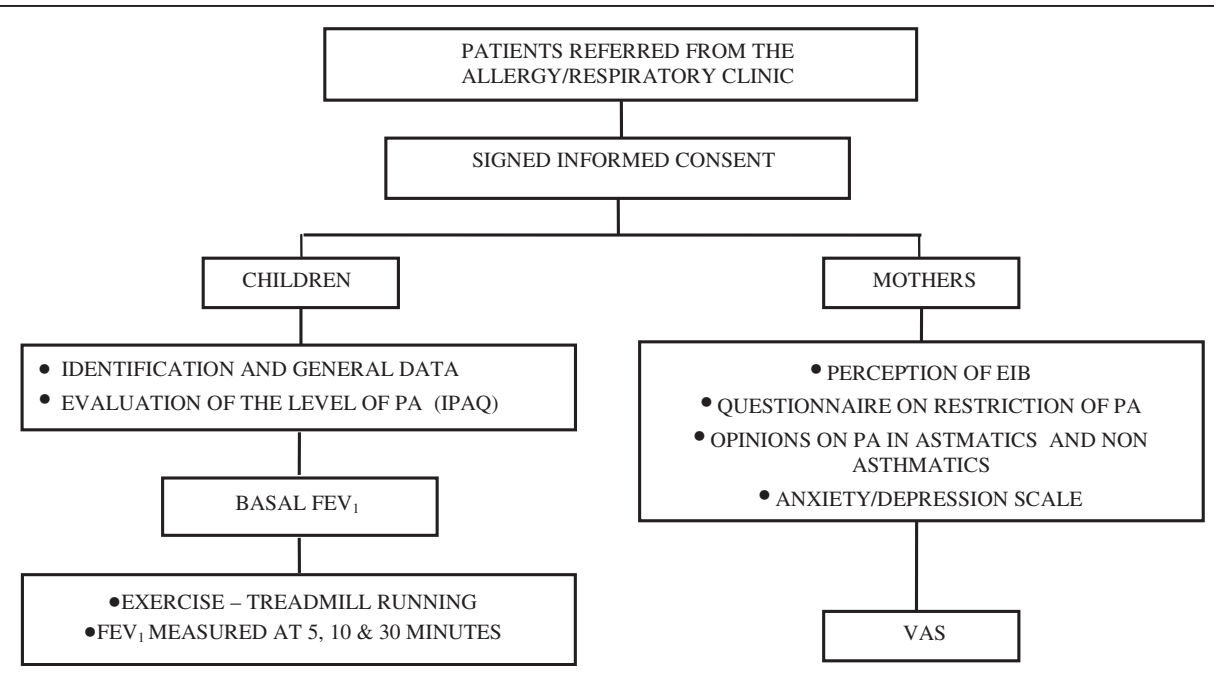

Figure 1 Study flow-chart. 
Table 1 General characteristics of the asthmatic children and adolescents

\begin{tabular}{|c|c|}
\hline & Offspring \\
\hline Total (n) & 115 \\
\hline Age - years (average $\pm s d^{\ddagger}$ ) & $13,06 \pm 2.1$ \\
\hline Gender (M/F) & $67 / 48$ \\
\hline Weight - Kg (average \pm sd) & $47.5 \pm 11.8$ \\
\hline Height- $\mathrm{cm}$ (average $\pm \mathrm{sd}$ ) & $155.7 \pm 9.2$ \\
\hline $\mathrm{BMI}-\mathrm{Kg} / \mathrm{cm}^{2}$ (average $\pm \mathrm{sd}$ ) & $19.3 \pm 3.2$ \\
\hline \multicolumn{2}{|l|}{ Severity of the asthma - n (\%) } \\
\hline Intermittent and mild persistent & 70 (61\%) \\
\hline Moderate and severe & 45 (39\%) \\
\hline \multicolumn{2}{|l|}{ Medication - n (\%) } \\
\hline No medication & $7(6 \%)$ \\
\hline Only beta ${ }^{2}$-bronchodilators for relief & 77 (67\%) \\
\hline Preventive treatment* & $31(27 \%)$ \\
\hline \multicolumn{2}{|l|}{ Monthly family income ${ }^{\dagger}-\mathrm{n}(\%)$} \\
\hline$\leq 1$ minimum wage & $54(47 \%)$ \\
\hline$>1<2$ minimum wage & $42(37 \%)$ \\
\hline$\geq 2$ minimum wage & $19(16 \%)$ \\
\hline
\end{tabular}

*Inhaled steroids, whether or not associated with long-acting beta ${ }^{2}$ adrenergic bronchodilators. ${ }^{\dagger}$ Minimum monthly wage at the time of the survey $=280$ U\$ dollars. ${ }^{\ddagger}$ Standard deviation.

the mother's PA restriction were the mother's perception of dyspnea after the children running on the treadmill (VAS), mother's anxiety level and children's asthma severity (Table 3).

\section{Discussion}

Our results showed that more than one third of the mothers of asthmatic children and adolescents admitted imposing restrictions on their children's PA. This is probably a source of important conflicts of the mothers with themselves and with their children and may contribute to some of the children being less active. The factor that was most strongly associated with the mother's attitude to imposing restriction was the fear that their children would fall ill if they do exercise, followed, in decreasing order, by maternal perception of dyspnea presented by their children after running on a treadmill, the level of the mother's anxiety and asthma severity.

To find that almost all mothers recognize exercise as being important for children is encouraging. However, half of them admit fearing that their children will get sick if they do exercise and over one third believe that exercise is dangerous for children with asthma. These negative conceptions are in agreement with the findings of Lang et al. [15] in an urban population in the Northeast of the United States. They also found that these conceptions, associated with the idea that the children felt uncomfortable after exercising, were responsible for
Table 2 Factors associated with the mother's attitude towards physical activities - univariate analysis ( $n=115$ )

\begin{tabular}{llll}
\hline \multicolumn{3}{l}{ Mother's attitude } & \\
\cline { 2 - 3 } Restricts & $\begin{array}{l}\text { Does not } \\
\text { restrict }\end{array}$ & $\begin{array}{l}\text { OR } \\
(95 \% \mathrm{Cl})\end{array}$ & $\mathrm{p}$ \\
$\mathrm{n}$ & $\mathrm{n}$ & \\
$43(37 \%)$ & $72(63 \%)$ &
\end{tabular}

Does your child wheeze

and/or have asthma when

at play or taking part in sports?

Yes

$35(81 \%) \quad 41(57) \quad 3.3$

0.01

$1.3-8.1$

VAS* score after exercise

$<5 \mathrm{~cm}$

$22(51 \%) \quad 53(74 \%) \quad 0.4$

0.02

$\geq 5 \mathrm{~cm}$

$21(49 \%) \quad 19(26 \%) \quad 0.2-0.8$

Is doing exercise

important for children?

Yes

$42(98 \%) \quad 69(96 \%) \quad 1.8$

$>0.99$

$0.2-18.1$

Are you afraid that your child will fall ill if he/she does exercise?

Yes

$32(74 \%) \quad 24(33 \%) \quad 5.8$

2.5-13.7

Is physical exercise dangerous for children with asthma?

Yes

$$
\begin{array}{ll}
23(53 \%) \quad 19(26 \%) & 2.6 \\
& \\
& 1.2-5.8
\end{array}
$$

\section{Anxiety: HADS $^{*}$}

$>9$

$\leq 9$

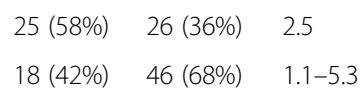

Depression - HADS ${ }^{*}$

$>9$

$13(30 \%) \quad 13(18 \%) \quad 2.0$

0.2

$\leq 9$

$30(70 \%) \quad 59(82 \%) \quad 0.8-4.8$

Asthma severity

Intermittent and mild persistent

Moderate and severe

$19(44 \%) \quad 51(71 \%) \quad 0.3$

EIB $^{\mathfrak{E}}$

Yes

$24(56 \%) \quad 21(29 \%) \quad 0.1-0.7$

$25(58 \%) \quad 27(38 \%) \quad 2.3$

$$
1.1-5.0
$$

*VAS - visual analog scale; ${ }^{¥}$ HADS - hospital anxiety and depression scale; ${ }^{\mathrm{E}} \mathrm{EIB}$ - exercise-induced bronchospasm.

asthmatic children's lower PA levels. Mansour et al. [29] also found that parents who were misinformed and regarded asthma as a barrier to doing PA unnecessarily restricted their children's participation in sports and games. 
Table 3 Factors associated with the mother's physical activities restriction - multivariate analysis*

\begin{tabular}{|c|c|c|}
\hline Factors & OR & $95 \% \mathrm{Cl}$ \\
\hline $\begin{array}{l}\text { Are you afraid that your child will fall ill if } \\
\text { he/she does exercise? }\end{array}$ & 7.96 & $2.97-21.29$ \\
\hline $\begin{array}{l}\text { Dyspnea perception } 5 \mathrm{~min} \text { after exercise - } \\
\text { VAS score }\end{array}$ & 3.27 & $1.20-8.92$ \\
\hline Anxiety - HADS & 3.36 & $1.30-8.70$ \\
\hline Asthma severity & 2.59 & $1.03-6.50$ \\
\hline
\end{tabular}

*Logistic regression; VAS - visual analog scale; HADS - hospital anxiety and depression scale; $\mathrm{OR}$ - odds ratio; $95 \% \mathrm{Cl}$ - ninety five percent confidence interval.

Parent's conceptions and attitudes towards sports and other types of PA may influence children's own perception of their ability to participate $[11,12]$ and those who attribute risks to children and adolescents with chronic diseases taking part in sports, games or playing around may contribute to their children having lower self-esteem and discourage them from doing PA [14]. On the other hand, Feredey et al. [13] observed that when parents had positive attitudes and opinions regarding doing physical activity, their children were more involved and committed to sports.

We cannot overlook the fact that a larger percentage of mothers than the one we found may be preventing their children from doing PA, given the number of mothers who claimed not to restrict their children's PA but responded affirmatively to the questions "Is exercise dangerous for children with asthma?" and "Are you afraid that your child may fall if he/she does exercise?". Mansour et al. [29] and Williams et al. [12] reported that even parents who say they do not limit their children's physical activity are distressed by the possibility of children's worsening of asthma symptoms which suggests that they may be, consciously or unconsciously, restricting or, at least, not encouraging their children to do such activities.

Mothers may also be preventing their children from doing PA based on the symptoms they perceive when their children are playing or taking part in sports. Firrincieli et al. [30], investigating physical activity in 3 to 5 year-old children, found that those with a history of asthma or wheezing in the last 12 months or that had been to an emergency room because of asthma were less active and suggest that this could be related to parents restricting the physical activities of their children.

The univariate analysis showed an association between the restrictive attitude of mothers and the occurrence of EIB but this association did not remain significant in the multivariate analysis. The perception of symptoms of dyspnea associated with physical activity both by mothers and by the patients themselves is flawed and is, very often, more related to a lack of being physically fit or to clinical states other than EIB. The diagnosis of EIB based solely on the perception of the symptoms should be taken with caution in the absence of any objective proof $[7,31]$.

Our findings also showed that the mother's level of anxiety was associated with their restrictive attitude to their children doing PA. No articles in the literature were found that have investigated this association. No association of the mother's level of anxiety was found between the severity of the asthma or with the perception of dyspnea measured by the visual analogue scale. The presence of higher levels of maternal depression was another hypothetical factor that we considered as being able to influence the mother's attitude, but no significant association was found.

The severity of asthma was associated with mothers' restriction on physical activity in the multivariate analysis but, in spite of this, no significant association was found between the severity of asthma and the children's PA levels. Mancuso et al. [32] reported an association of lower PA levels and asthma severity but in their research the patients themselves expressed the belief that exercise was not good for asthma.

Despite the importance of physical activity for children and adolescents with asthma, more than one third (35\%) of the patients evaluated were considered inactive. This proportion did not differ from what has been found among students from 9th grade (12-16 years old) in the city of Recife who were evaluated in a large populationbased epidemiological study conducted in Brazil (National Survey of the Health of Schoolchildren) [33]. Only a small proportion (14\%) of our children and adolescents sample was engaged regularly in sports. In the remaining, PA was restricted to walking or cycling between home and school, occasional participation in football matches (soccer), games and other leisure activities.

Although a considerable number of the children in the study were classified as inactive, mothers restricting PA was not the determining factor for this. It is likely that despite mothers advising their children to avoid PA, they do not follow this advice and take part in PA when not under supervision, such as, in school. Some authors have shown that mothers have little knowledge of their children's PA $[10,12,18]$. Interestingly, in a previous study we found an association between children's reports of mother's restrictive attitudes and a lower level of PA, suggesting that when the mother's prohibitions are taken into account by their children this can have an impact on their level of physical activities [34].

A possible bias in our results is the fact that the instrument used to assess the PA level in children and adolescents - IPAQ - does not provide precise and direct measurements of energy expenditure and questionnaires typically require respondents to recall their activities over the determined period [24]. Although assessing the PA level by using questionnaires for children and adolescents 
is still an issue of debate in the literature [35,36], we used the short version of the International Physical Activity Questionnaire (IPAQ) that is validated and formally translated to Portuguese (Brazil) has acceptable measurement properties on data obtained on participants from 12 countries, including Brazil [24]. Another possible bias is that it was not included in the questionnaire a query for mothers about maternal asthma. Mothers that have experienced the feeling of dyspnea could impose more physical activity restriction to their children.

\section{Conclusions}

Many mothers of asthmatics children and adolescents believe that PA can worsen their children's asthma symptoms and this is the most important factor associated with their restrictive attitudes towards physical activities. As this behavior may discourage children from having an active healthy lifestyle, our findings reinforce the need for physicians and health professionals to address and discuss these misconceptions with patients and their caregivers. With appropriate evaluation, effective preventive treatment and counseling these children do not need to avoid physical activities and can be stimulated to have a fully active life.

\section{Competing interests}

The authors declare that they have no competing interests.

\section{Authors' contributions}

FMNAD Contributed to data collection and analysis. MAVC Contributed to data collection and analysis. ARS Contributed to Sudy design and data analysis. DMP Contributed to Study design and data collection. ESCS Contributed to Data analysis and manuscript writing. JAR Contributed to Study conception, data analysis and interpretation and manuscript writing. All authors read and approved the final manuscript.

\section{Acknowledgements}

To Miss Selma Monteiro for her help with spirometric tests, to Miss Camila Sarteschi for statistical advise and to Professor David Bousfield for the technical assistance with the manuscript.

\section{Author details}

${ }^{1}$ Hospital Agamenon Magalhães, Pos-graduação em Ciências da Saúde. Universidade Federal de Pernambuco, Recife, Brazil. ${ }^{2}$ Universidade de Pernambuco, Petrolina, Brazil. ${ }^{3}$ Center for Research in Allergy and Clinical Immunology. Pediatrics Department, Universidade Federal de Pernambuco, Recife, Brazil. ${ }^{4}$ Center for Research in Allergy and Clinical Immunology. Clinical Medicine Department - Pneumology, Universidade Federal de Pernambuco, Recife, Brazil.

Received: 17 December 2013 Accepted: 17 March 2014 Published: 28 March 2014

\section{References}

1. Fanelli A, Cabral ALB, Neder JA, Martins MA, Carvalho CRF: Exercise training on disease control and quality of life in asthmatic children. Med Sci Sports Exerc 2007, 39(9):1474-1480.

2. van Veldhoven NHMJ, Vermeer A, Bogaard JM, Hessels MGP, Wijnroks $L$, Colland VT, van Essen-Zandvliet EEM: Children with asthma and physical exercise: effects of an exercise programme. Clin Rehabil 2001, 15:360-370.

3. Rasmussen F, Lambrechtsen J, Siersted HC, Hansen HS, Hansen NC: Low physical fitness in childhood is associated with the development of asthma in young adulthood: the Odense schoolchild study. Eur Respir J 2000, 16:866-870
4. Dencker M, Thorsson O, Karlsson MK, Linden C, Svensson J, Wollmer P, Andersen LB: Daily physical activity and its relation to aerobic fitness in children aged 8-11 years. Eur J Appl Physiol 2006, 96:587-592.

5. Neder JA, Nery LE, Silva AC, Cabral AL, Fernandes AL: Short-term effects of aerobic training in the clinical management of moderate to severe asthma in children. Thorax 1999, 54(3):202-206.

6. Khan DA: Exercise-induced bronchoconstriction: burden and prevalence. Allergy Asthma Proc 2012, 33:1-6.

7. Weiler JM, Anderson SD, Randolph C, Bonini S, Craig TJ, Pearlman DS, Rundell KW, Silvers WS, Storms WW, Bernstein DI, Blessing-Moore J, Cox L, Khan DA, Lang DM, Nicklas RA, Oppenheimer J, Portnoy JM, Schuller DE, Spector SL, Tilles SA, Wallace D, Henderson W, Schwartz L, Kaufman D, Nsouli T, Shieken L, Rosario N: Pathogenesis, prevalence, diagnosis, and management of exercise-induced bronchoconstriction: a practice parameter. American Academy of Allergy, Asthma and Immunology; American College of Allergy, Asthma and Immunology; Joint Council of Allergy, Asthma and Immunology. Ann Allergy Asthma Immunol 2010, 105(6 Suppl):S1-S47.

8. Global Initiative for Asthma - GINA [homepage on the Internet]: Bethesda: Global Initiative for Asthma. Global Strategy for Asthma Management and Prevention. [Last updated in Jan 2010; accessed on 16 Apr 2009]. Available at: www.ginasthma.com.

9. Welsh L, Kemp JG, Roberts RGD: Effects of physical conditioning on children and adolescents with asthma. Sports Med 2005, 35(2):127-141.

10. Ostrom NK, Eid NS, Craig TJ, Colice GL, Hayden ML, Parsons JP, Stoloff SW: Exercise-induced bronchospasm in children with asthma in the United States: results from the exercise-induced bronchospasm landmark survey. Allergy Asthma Proc 2011, 32(6):425-430.

11. Pianosi $\mathrm{P}$, Davis $\mathrm{H}$ : Determinants of physical fitness in children with asthma. Pediatrics 2004, 113:225-229.

12. Williams B, Powell A, Hoskins G, Neville R: Exploring and explaining low participation in physical activity among children and young people with asthma: a review. BMC Fam Pract 2008, 9:40-51.

13. Fereday J, Macdougall C, Spizzo M, Darbyshire P, Schiller W: "There's nothing I can't do - I just put my mind to anything and I can do it": a qualitative analysis of how children with chronic disease and their parents account for and manage physical activity. BMC Pediatr 2009, 9(1):1-16.

14. Vitulano LA: Psychosocial issues for children and adolescents with chronic illness: self-esteem, school functioning and sports participation. Child Adolesc Psychiatric Clin N Am 2003, 12:585-592.

15. Lang D, Butz A, Duggan A, Serwint J: Physical activity in urban schoolaged children with asthma. Pediatr 2004, 113:341-346.

16. Tosca MA, Silvestri M, Olcese R, Pistorio A, Rossi GA, Ciprandi G: Breathlessness perception assessed by visual analogue scale and lung function in children with asthma: a real-life study. Pediatr Allergy Immunol 2012, 23(6):537-542.

17. Rapino D, Consilvio NP, Scaparrotta A, Cingolani A, Attanasi M, Di Pillo S, Verini M, Chiarelli F: Relationship between exercise-induced bronchospasm (EIB) and asthma control test (ACT) in asthmatic children. J Asthma 2011, 48(10):1081-1084.

18. Young B, Fitch GE, Dixon-Woods M, Lambert PC, Brooke AM: Parents' accounts of wheeze and asthma related symptoms: a qualitative study. Arch Dis Child 2002, 87:131-134.

19. Cane RS, Ranganathan SA, Mckenzie SA: What do parents of wheezy children understand by "wheeze"? Arch Dis Child 2000, 82:327-332

20. Davis KJ, DiSantostefano R, Peden DB: Is Johnny wheezing? Parent-child agreement in the childhood asthma in America survey. Pediatr Allergy Immunol 2011, 22:31-35.

21. American Thoracic Society: Guidelines for methacholine and exercise challenge testing-1999. Am J Respir Crit Care Med 2000, 161:309-329.

22. World Health Organization, WHO: Physical Status: the use and interpretation of anthropometry. Report of a WHO Expert Committee. Technical Report Series No. 854, Geneva: World Health Organization; 1995:263-311.

23. Guedes DP, Lopes CC, Guedes JERP: Reprodutibilidade e validade do Questionário Internacional de Atividade Física em adolescentes. Rev Bras Med Esporte 2005, 1:151-158.

24. Craig CL, Marshall AL, Sjostrom M, Bauman AE, Booth ML, Ainsworth BE, Pratt M, Ekelund U, Yngve A, Sallis JM, Oja P: International Physical Activity Questionnaire (IPAQ): 12-country reliability and validity. Med Sci Sports Exerc 2003, 35:1381-1395. 
25. Snaith RP: The hospital anxiety and depression scale. Health Qual Life Outcomes 2003, 1:29-33.

26. Botega NJ, Bio MR, Zomignani MA, Garcia C, Pereira WAB: Transtornos do humor em enfermaria de clínica médica e validação de escala de medida (HAD) de ansiedade e depressão. Rev Saude Pública 1995, 29(5):355-363.

27. Miller MR, Hankinson J, Brusasco V, Burgos F, Casaburi R, Coates A, Crapo R, Enright $P$, van der Grinten $C P$, Gustafsson $P$, Jensen $R$, Johnson DC, Maclntyre N, McKay R, Navajas D, Pedersen OF, Pellegrino R, Viegi G, Wanger J: Series "ATS/ERS task force: standardisation of lung function testing". Eur Respir J 2005, 26:319-338.

28. Pneumobil P: Dados preliminares do Inquérito Epidemiológico, Clínico e Funcional do aparelho respiratório em indivíduos adultos e crianças em cidades do Estado de São Paulo e Belo Horizonte. J Pediatr (Rio J) 1991, 67:18-24.

29. Mansour ME, Lanphear BP, Dewitt TG: Barriers to asthma care in urban children: parent perspectives. Pediatrics 2000, 106(3):512-519.

30. Firrincieli V, Keller A, Ehrensberger R, Platts-Mills J, Shufflebarger C, Geldmaker B, Platts-Mills T: Decreased physical activity among head start children with a history of wheezing: use of an accelerometer to measure activity. Pediatr Pulmonol 2005, 40(1):57-63.

31. Abu-Hasan M, Tannous B, Weinberger M: Exercise-induced dyspnea in children and adolescents: if not asthma then what? Ann Allergy Asthma Immunol 2005, 94:366-371.

32. Mancuso CA, Sayles W, Robbins L, Phillips EG, Ravenell K, Duffy C, Wenderoth S, Charlson ME: Barriers and facilitators to healthy physical activity in asthma patients. J Asthma 2006, 43(2):137-143.

33. Brasil, Ministério da Saúde, IBGE, Ministério do planejamento Orçamento e Gestão: Pesquisa nacional por amostra de domicílios 2008, v. 29. Rio de Janeiro: IBGE; 2009. Disponível em: www.ibge.gov.br/home/estatistica/ populacao/pense/pense.pdf.

34. Correia MAV, Rizzo JA, Sarinho SW, Sarinho ESC, Medeiros D, Assis FMN: Effect of exercise-induced bronchospasm and parental beliefs on physical activity of asthmatic adolescents from a tropical region. Ann Allergy Asthma Immunol 2012, 108(4):249-253.

35. Hagströmer M, Bergman P, De Bourdeaudhuij I, Ortega FB, Ruiz JR, Manios Y, Rey-López JP, Phillipp K, von Berlepsch J, Sjöström M, HELENA Study Group: Concurrent validity of a modified version of the International Physical Activity Questionnaire (IPAQ-A) in European adolescents: The HELENA Study. Int J Obes 2008, 32(Suppl 5):S42-S48.

36. Hallal PC, Gomez LF, Parra DC, Lobelo F, Mosquera J, Florindo AA, Reis RS, Pratt M, Sarmiento OL: Lessons learned after 10 years of IPAQ use in Brazil and Colombia. J Phys Act Health 2010, 7(Suppl 2):S259-S264.

doi:10.1186/1471-2458-14-287

Cite this article as: Dantas et al:: Mothers impose physical activity restrictions on their asthmatic children and adolescents: an analytical cross-sectional study. BMC Public Health 2014 14:287.

\section{Submit your next manuscript to BioMed Central and take full advantage of:}

- Convenient online submission

- Thorough peer review

- No space constraints or color figure charges

- Immediate publication on acceptance

- Inclusion in PubMed, CAS, Scopus and Google Scholar

- Research which is freely available for redistribution 